

\section{Article Artículo Paper Les habilitats per a la 7 vida com a estratègia pedagògica de salut}

\section{Elisabet Esteva ${ }^{1}$}

Anna Loste ${ }^{1}$

\section{Caroline Mowatt ${ }^{1}$}

\section{Resum}

En aquest article les autores ens presenten l'enfocament dels determinants socials de la salut, juntament amb la mirada salutogènica i el treball de les habilitats per a la vida per a entendre millor el recorregut vital i emocional dels joves en contextos de migració, fugint de visions estereotipades i paternalistes. Les autores consideren clau que s'ofereixin espais als infants $\mathrm{i}$ joves per desenvolupar les seves habilitats per a la vida, que són aquelles competències necessàries per assolir un comportament adaptatiu que els permeti afrontar efectivament les demandes i els desafiaments de la vida diària. Argumenten també que una recerca recent duta a terme amb infants $\mathrm{i}$ joves migrats sense referents adults a Irlanda, constatava que la idea de continuïtat i de donar un sentit a les seves vides els ajudava, en la majoria dels casos, en els seus processos identitaris personals i els ajudava a augmentar la seva resiliència. D'aquí el valor que donen al treball de les 10 habilitats per a la vida i a l'enfortiment del Sentit de Coherència. Finalment les autores presenten de 
quina manera treballen aquestes habilitats, posant com a exemple el programa "Sigues tu, eines i actius per a la salut" de Dipsalut.

Paraules clau: habilitats per a la vida, sentit de coherència, determinants socials de la salut, salutogènesi, joves migrats

\begin{abstract}
In this article the authors present us with the approach of the social determinants of health, together with the salutogenic gaze and the work of life skills to better understand the life and emotional journey of young people in migration contexts, fleeing from stereotyped and paternalistic views. The authors consider it key to provide spaces for children and young people to develop their life skills, which are those skills needed to achieve adaptive behaviour that allows them to effectively meet the demands and challenges of daily life. They also argue that recent research conducted with migrant children and young people without adult references in Ireland found that the idea of continuity and giving meaning to their lives helped them, in most cases, in their personal identity processes, and it helped them increase their resilience. Hence the value they give to the work of the 10 life skills and to the strengthening of the Sense of Coherence. Finally, the authors present how these skills work, giving as an example the program "Be you, tools and assets for health" of Dipsalut.
\end{abstract}

Kew words: life skills, sense of coherence, social determinants of health, salutogenesis, young migrants 


\section{La salut $i$ els determinats socials}

La salut és un dret humà fonamental, de manera que les polítiques i els programes han d'oferir estratègies i solucions que permetin afrontar i corregir les desigualtats, les pràctiques discriminatòries i les relacions de poder injustes. En especial pel que fa la als menors i tal com proclama la Convenció sobre els Drets de la Infancia (1989), els estats han de vetllar per la protecció i la promoció de la salut dels infants des d'un punt de vista holístic, de manera que cal garantir el seu desenvolupament físic i mental, però també l'espiritual, moral i social. Així mateix, cal vetllar per l'interès superior de l'infant en les polítiques públiques per tal de no vulnerar aquests drets fonamentals dels infants $i$ joves.

Els factors que intervenen en la salut de les persones són complexos, estan interrelacionats i van molt més enllà de la biologia, la genètica o l'atenció sanitària (Country Health Rankings Model, 2010). Tal com explicita el marc teòric dels determinants socials en salut (OMS, 2009), la salut està molt lligada a les circumstàncies en les quals les persones neixen, creixen, viuen, treballen i envelleixen. En paraules de Michael Marmot (2000), gran referent en el camp de l'epidemiologia social i els determinants socials de la salut; per la teva salut té més importància el codi postal que el codi genètic.

Existeix una clara relació entre els estils de vida i les condicions de vida, de manera que no tothom té els recursos i les oportunitats per menjar de manera saludable, fer activitat física o controlar l'estrès de manera adequada. Aquest fet no afecta només a les persones i els països més desfavorits socioeconòmicament, sinó que es tracta d'un fenomen global. És el que s'anomena gradient social de salut, que suposa que a mesura que baixem l'escala social disminueix l'esperança de vida i són més comunes les malalties.

Per tant, no totes les persones tenen les mateixes oportunitats, sinó que les posicions de poder i privilegi generen diferències en la salut i el benestar. Aquests eixos de desigualtat corresponen a la classe social, el gènere, l'edat, lètnia, el territori, l'origen... Habitualment s'analitzen de manera aillada, sense tenir en compte que la posició de les persones és el resultat del creuament dels diferents eixos de desigualtat. La interacció entre ells es coneix com a interseccionalitat (Crenshaw, 1989), aquest terme prové del moviment feminista negre i permet explicar com les formes dexclusió estan interconnectades i donen lloc a diferents formes de discriminació i injustícia social. De fet, la intersecció de diferents eixos genera 
noves situacions de desigualtat que van més enllà de la simple suma d'aquests. Per això, és necessari atendre aquesta complexitat a l'hora de desenvolupar polítiques més inclusives.

En definitiva, és imprescindible una mirada sota el marc dels determinants per a la salut per entendre que no totes les persones neixen amb les mateixes oportunitats i que per tant, cal destinar més recursos a aquells col·lectius amb més dificultats (Marmot i Wilkinson, 2003). Aquest marc teòric, ens ajuda a entendre de millor manera el recorregut vital i emocional dels joves en contextos de migració, fugint de visions estereotipades i paternalismes caducs.

\section{Les Habilitats per a la Vida i el Sentit de Coherència (SOC)}

En la nostra societat actual, complexa i diversa, sabem que la informació és molt important, però no suficient per promoure un estil de vida saludable i respectuós amb les altres persones i amb l'entorn. En aquest sentit, és clau oferir espais als infants i joves per desenvolupar les seves habilitats per a la vida, que són aquelles competències necessàries per assolir un comportament adaptatiu que els permeti afrontar efectivament les demandes $i$ els desafiaments de la vida diària (WHO, 2003). En concret són un conjunt de competències psicosocials i habilitats interpersonals que ajuden a les persones a prendre decisions informades, resoldre problemes, pensar críticament i creativament, comunicar-se eficaçment, construir relacions saludables, empatitzar i afrontar i gestionar les seves vides d'una manera saludable i productiva. Les habilitats per a la vida poden anar dirigides a accions personals, envers les altres persones o bé enfocades a canviar l'entorn per tal que aquest sigui promotor de la salut. Un estudi que analitza l'itinerari educatiu de joves ex-tutelats posa de manifest que "la resiliència dels infants $i$ joves que han viscut en situacions de vulnerabilitat i/o marginació és un dels aspectes clau en el seu èxit educatiu/laboral i relacional" (Montserrat, Casas, Malo i Bertran, 2011)

Lligat amb el concepte de salut positiu i holístic, fa gairebé quaranta anys, el metge i sociòleg Aaron Antonovsky va plantejar la teoria salutogènica (Antonovsky, 1979), un enfocament nou fins aleshores. L'autor va dur a terme un estudi amb dones jueves que havien sobreviscut a l'holocaust. Va observar que la majoria tenien molt mala salut, però hi havia un petit grup que, tot i haver patit el mateix sofriment, gaudien d'una gran qua- 
litat de vida. Es va preguntar per què i va descobrir que aquestes dones tenien molt elevat el que ell va anomenar sentit de coherència (SOC) que va relacionar amb tres factors: la capacitat d'entendre el món, la destresa per aprofitar els recursos que tenim a l'abast i, el més important, la confiança que la vida té un sentit.

En un estudi que es va fer amb infants i joves migrats sense referents adults a Irlanda, que analitzava quines estratègies havien utilitzat aquests joves per enfrontar-se a tot el periple migratori, constatava que la idea de continuïtat i de donar un sentit a les seves vides els ajudava, en la majoria dels casos, en els seus processos identitaris personals i els ajudava a augmentar la seva resiliència (Raghallaighi i Gilligan, 2010).

L'any 2007 es va crear un grup de treball internacional constituït per les persones expertes més destacades en promoció de la salut, amb l'objectiu d'estudiar, arreu del món, la relació entre el sentit de coherència i la salut. Els resultats estan sent encoratjadors. Destaquen que un SOC fort està associat, en general, amb un estil de vida saludable, com per exemple fer activitat física, tenir una bona alimentació, no fumar i, en general, tenir consums més respectuosos amb la pròpia salut i la de les altres persones. Així doncs, l'aprenentatge en les habilitats per a la vida i l'enfortiment del SOC poden esdevenir grans estratègies per incidir en la millora de la qualitat de vida dels infants i adolescents, en especial aquells més vulnerats socioeconòmicament.

\section{Com fomentem l'aprenentatge de les Habilitats per a la Vida?}

Les deu Habilitats per a la vida declarades per l'OMS l'any 2003 són: l'autoestima i control intern; el maneig dels sentiments i les emocions; el maneig de la tensió i l'estrès; la comunicació interpersonal; la negociació i el rebuig (ser capaç de comunicar-se de manera assertiva defensant la pròpia postura i escoltant a l'altre); l'empatia; la col-laboració i treball en equip; l'advocació i defensa (la capacitat de defensar a un grup, crear aliances i construir lideratges positius); presa de decisions i solució de problemes i pensament crític.

El paper de les persones professionals, que faciliten als joves l'aprenentatge de les habilitats per a la vida, esdevé clau a l'hora de desenvolupar aquesta estratègia pedagògica. Per aconseguir una intervenció efectiva i coherent és necessari que la persona facilitadora 
reconegui els propis valors i prejudicis i estigui disposada a fer un procés constant d'autoreflexió. És a dir que sigui conscient del llenguatge que utilitza, de les relacions de poder asimètriques que s'estableixen i del discurs propi que serà l'aixopluc de la intervenció.

Per assolir una significativitat en l'aprenentatge de les habilitats és important que hi hagi una coherència entre el contingut i la metodologia. Tant important és el què com el com. La persona que facilita l'aprenentatge ha de poder comunicar-se de manera coherent i respectuosa, parlant poc i escoltant molt, per entendre i no per donar una resposta; acostar-se als i a les joves des del respecte i l'horitzontalitat, posant en pràctica la comunicació assertiva; resumir les intervencions sense judici, fer retorn de preguntes propiciant la reflexió; acceptar els sentiments i emocions... En definitiva, ha de creure en les capacitats dels i les joves per poder-los acompanyar en la recerca de les seves pròpies respostes, respectant els diferents ritmes d'aprenentatge. Un estudi amb joves migrats sense acompanyament d'adults que es va portar a terme a Finlàndia i Suècia posava de manifest la sensació generalitzada de malestar davant l'infantilisme amb el que creien ser tractats pels adults referents de la societat acollidora. No sentien validades les seves experiències, sentien que se'ls posava en el mateix sac que altres joves que no havien viscut un periple migratori amb tot el que comporta: por, incertesa, dol... (Kaukko i Wernesjö, 2016). Si la persona adulta no és capaç de validar aquestes experiències, d'escoltar i de veure als i a les joves com a persones amb experiència i resiliència més enllà de la seva vulnerabilitat, molt difícilment podrà ser capaç de propiciar una millora en la seva salut i benestar.

\section{Proposta d'intervenció}

A l'hora de plantejar la intervenció, se sap que les persones professionals hem de prendre consciència dels nostres propis valors i prejudicis, ja que sovint, amb la millor de les intencions, en el nostre discurs podem reproduir estereotips que legitimin noves formes de racisme més subtils, però igualment nocives (Buraschi i Aguilar, 2015).

Per aquest motiu, considerem que en primer lloc cal un procés formatiu i reflexiu de l'equip que ha de fer la intervenció, sobretot en relació al que suposa incloure la perspectiva intercultural en les accions de salut amb joves de contextos migratoris. En aquest sentit, esdevé clau tenir en compte que el racisme es basa en un sistema de desigualtat social, ex- 
clusió i dominació d'uns grups sobre els altres i no en algunes actituds individuals causades per "por" o "ignorància". Finalment no cal oblidar els marcs teòrics dels determinants de la salut i la interseccionalitat, que postulen que el racisme es creua amb altres eixos de dominació com el classisme o el sexisme i per tant no afecta de la mateixa manera a totes les persones. Així doncs, la incorporació de la perspectiva intercultural no s'hauria de centrar exclusivament en les accions que fem amb els i les joves, sinó que hauria de formar part de manera transversal de totes les nostres accions: comunicacions, formacions, notícies, informes tècnics, relació amb altres administracions...

La nostra proposta d'intervenció amb joves s'emmarca dins el programa "Sigues tu, eines i actius per a la salut" de Dipsalut, que està dissenyat per entrenar les habilitats per a la vida d'infants i adolescents en el marc de l'educació formal. No obstant això, les activitats es poden adaptar a d'altres contextos com el del lleure educatiu o les associacions juvenils.

En funció de les edats i a partir dels recursos materials (contes, historietes, àlbums de cromos, vídeos...), s'inicia una reflexió a l'aula sobre aspectes com ara la importància de respectar-se a un mateix i als altres, de saber prendre decisions, d'afrontar els desafiaments de manera positiva o de mantenir el sentit crític enfront de les pressions del grup. Els materials de secundària permeten treballar les 10 habilitats per a la vida i el sentit de coherència sota els eixos de consums, afectivitat i sexualitat, convivència i participació.

La planificació consisteix en dur a terme entre 15 i 20 sessions d'aproximadament una hora de durada en base als 4 eixos que hem exposat. Es comença amb una sessió introductòria i es va avançant amb les altres propostes pedagògiques; una per cadascuna de les 10 habilitats per a la vida i 10 més per treballar el sentit de coherència.

A continuació us proposem alguns exemples d'activitats del "Sigues tu" per treballar el sentit de coherència i habilitats com: la presa de decisions i solució de problemes, el pensament crític, l'empatia, l'autoestima o la col-laboració i el treball en equip:

- E1 refugi subterrani. Aquesta dinàmica consisteix en dividir les persones participants en 4 o 5 grups (en funció del nombre poden ser menys). Els demanarem que escullin a 6 persones, de les 12 proposades, per salvar-los la vida a partir de la 
descripció que es fa de cadascuna d'elles (edat, malalties o trastorns, ocupació, orientació sexual..). Caldrà argumentar la decisió. Pot servir per treballar les diferències entre la presa de decisions individual i grupal, els diferents estils de lideratge i la dificultat de consensuar decisions en les quals intervenen valors i judicis morals ${ }^{2}$.

- Càmera oculta. Es comença visionant una càmera oculta on es mostren les reaccions de diferents persones davant una actitud clarament racista i de rebuig. Com reaccionariem nosaltres davant aquesta situació? Tindriem la capacitat d'actuar o adoptariem una actitud passiva o de rebuig? Alguna vegada hem estat victimes de conductes racistes o discriminatòries? Ens permet treballar els prejudicis, la discriminació i les habilitats d'advocació i defensa, d'empatia, de pensament crític i de presa de decisions i solució de problemes. Podeu proposar al grup de joves que busqui informació als mitjans de comunicació sobre alguna notícia relacionada amb la immigració i que analitzin si es reflecteixen o no estereotips relacionats amb algunes cultures o nacionalitats. Poden fer un escrit en el qual reflexionin sobre això: La informació és objectiva? Quina visió es dona de les persones immigrants? Positiva o negativa? Per què? Poseu exemples del text que donin suport a les vostres afirmacions ${ }^{3}$.

- Atracció dels pols oposats. Aquesta dinàmica proposa que, a partir d'un personatge famós, el o la jove es pugui identificar amb alguna de les seves qualitats $i$ posteriorment explorar la polaritat contrària. Permet descobrir debilitats i oportunitats pròpies per autoconstruïr-se i avaluar-se. Ens pot ajudar a treballar les habilitats d'autoestima i control intern ${ }^{4}$. Com a tancament us proposem visionar el vídeo Què en pensem dels adolescents?, en el que apareixen un seguit de persones adultes opinant de forma negativa i estereotipada sobre l'adolescència. A la part final del vídeo es demostra que aquests judicis tan pessimistes sobre les capacitats dels i les joves estan molt allunyats de la realitat ${ }^{5}$.

2. En aquest enllaç podeu trobar la descripció completa de l'activitat: https://www.siguestu.cat/ca/recursos2/1/385-dinamica--refugi-subterrani.html

3. Aquest és l'enllaç que dona accés al vídeo: https://www.siguestu.cat/ca/recursos.html?search\%5B\%5D=Interculturalitat

4. Aquí podeu trobar la descripció completa de l'activitat: https://www.siguestu.cat/ca/recursos2/1/1326-dinamica--atraccio-pols-oposats.html

5. Aquí podeu trobar l'enllaç al vídeo: https://www.siguestu.cat/ca/recursos2/1/1599-que-en-pensem-dels-adolescents--prejudicis.html 


\section{Bibliografia}

Antonovsky, A. (1979). Health, stress, and coping. San Francisco: Jossey-Bass Inc.

Assemblea General Nacions Unides (1989). Convenció sobre els Drets dels Infants. United Nations, Treaty Series, vol.1577, p. 3.

Buraschi, D. i Aguilar-Idáñez, M.J.(2015). “Nuevas herramientas conceptuales para una intervención social antirracista”. V Congreso anual REPS Desigualdad y democracia: politicas públicas y participación social. Barcelona, 5 i 6 de febrer de 2015. Disponible a: http://repsbarcelona2015.es/panel-7-inmigracion/

Country Health Rankings Model (2010). University of Wisconsin Population Health Institute and the Robert Wood Johnson Foundation. Disponible a: https://www. countyhealthrankings.org/resources/county-health-rankings-model

Crenshaw, K. (1989). "Demarginalizing the Intersection of Race and Sex: A Black Feminist Critique of Antidiscrimination Doctrine, Feminist Theory and Antiracist Politics”. University of Chicago Legal Forum, vol. 1989 (1), article 8, 139-67.

Dipsalut. Programa “Sigues tu: eines i actius per a la salut". Dipsalut. Diputació de Girona. Disponible a: https://www.siguestu.cat/ [Data de consulta: 15 de juliol de 2020]

Kaukko, I Wernesjö,U. (2017). "Belonging and participation in liminality: Unaccompanied children in Finland and Sweden”. Childhood, vol. 24 (1) 7-20.

Marmot, M. (2000). The Status Syndrome. New York: Times books.

Marmot, M i Wilkinson, R. (2003). Los Determinantes Sociales en salud: Los Hechos probados. Organització Mundial de la Salut.

Montserrat, C., Casas, F., Malo, S. I Bertran, I. (2011). Los itinerarios educativos de los jóvenes ex-tutelados. Madrid: Ministerio de Sanidad, Política Social e Igualdad. 
OMS (2009). Subsanar las desigualdades de una generación. Ginebra: Organització Mundial de la salut. Comissió de Determinants Socials de la Salut.

Raghallaigh, M. N. i Gilligan, R. (2010). "Active survival in the lives of unaccompanied minors: Coping strategies, resilience, and the relevance of religion". Child and Family Social Work, 15 (2), 226-237. https://doi.org/10.1111/j.1365-2206.2009.00663.x

World Health Organization (2003). Skills for health. Skills-based health education including life skills: an important component of a child-friendly/health-promoting school. World Health Organization. Diponible a : https://apps.who.int/iris/handle/10665/42818 
Xedagogia i Treball Social

Revista de Ciències Socials Aplicades

Edita: Universitat de Girona

Disseny i maquetació: info@clam.cat · 647427732

Dipòsit Legal: GI.904-2010

ISSN: 2013-9063 